\title{
Preface from the Honorary Editor in Chief
}

\author{
Hailing Tu ${ }^{1}$
}

(c) The Nonferrous Metals Society of China 2019

Tungsten is a remarkable rare metal with many attractive properties, and its alloys and compounds have been widely used in cutting tools, alloying, armaments, integration circuits, steel and aeronautics industries. The strategic role of tungsten-based materials has been reflected in disciplines of metallurgy, aerospace, information and life sciences, though incandescent lamps have been gradually fading away from household lighting. Furthermore, the past decade has seen increasing attention to transition metal dichalcogenides utilized in electronics and tungsten alloys for future applications in fusion apparatuses. In addition, it has been found that tungsten has a low potential to cause harm to animals and humans at environmentally relevant concentrations.

Jiangxi Province, located in the southeast of China, has abundant tungsten resources and a long history of mining, ore dressing and smelting. Under the backgrounds of rational use of resources and innovation promotion, Jiangxi University of Science and Technology and the Nonferrous Metals Society of China have jointly established a new journal, Tungsten (ISSN: 2661-8028 (print version), 26618036 (electronic version)). Tungsten is a peer-reviewed, international and interdisciplinary academic journal that showcases all aspects of research findings of tungsten and related metals including molybdenum, cobalt, vanadium, tantalum, niobium and rhenium, as well as their alloys and compounds. The journal aims to provide a broad-scale platform of not only sharing and exchanging scientific results, but also a better understanding of development and innovative trends in materials engineering and applications. Submissions are solicited in, but not limited to, the following topics: advanced metallurgical processes, recycling and reuse, hard and refractory alloys, energy conversion and storage materials, nuclear materials, electronic materials, low-dimensional materials, surface treatment, 3D printing, medical applications, and simulation and modeling. The

Hailing Tu

wtec@grinm.com

1 GRINM Group Co., Ltd., Beijing 100088, China journal also embraces commentaries, reviews and perspectives covering the latest breakthroughs and developments.

Tungsten has assembled a prestigious editorial board composed of 30 leading scientists and professors from ten countries, who are specialized in diverse research areas to maintain the academic standard of the journal and to ensure the high quality of the accepted articles. We fully understand that the journal cannot flourish without the vigorous support of authors, reviewers, readers and stakeholders from various circles. On behalf of the editorial board, I hereby would like to extend our sincere appreciation for their significant contributions to the publication of this inaugural issue.

Finally, we wish Tungsten, with the up-to-date research results contributed by scientists and engineers worldwide, every success and look forward to bringing it to a longstanding and distinguished position in the scientific literature.

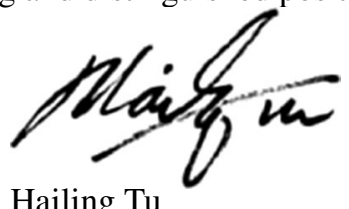

Hailing Tu

March 18, 2019

Publisher's Note Springer Nature remains neutral with regard to jurisdictional claims in published maps and institutional affiliations

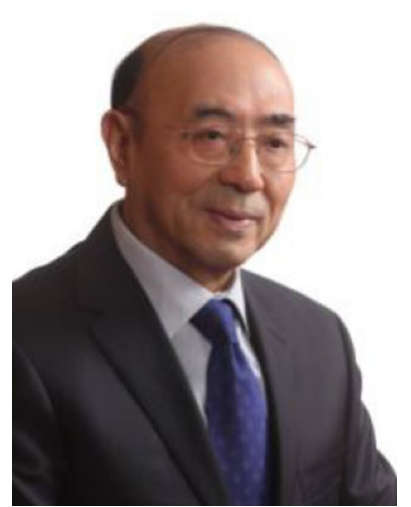

Dr. Hailing Tu is the honorary president of General Research Institute for Nonferrous Metals (GRINM) of Beijing and the director of science and technology committee of GRINM Group Co., Ltd. He received a $\mathrm{PhD}$ degree in solid state physics from the University of Bath in 1983 and had been a senior visiting scholar at North Carolina State University from 1994 to 1995. He was elected a member of the Chinese Academy of 
Engineering in 2007. He once served as a member of the Standing Committee of China Association for Science and Technology, vice president of Chinese Materials Research Society, vice president of the Nonferrous Metals Society of China, vice president of Chinese Society of Rare Earths, vice president of China Semiconductor Industry Association, and vice president of China Electronics Materials Industry Association. Dr. Tu has been engaged in fabrication and characterization of silicon, compound semiconductors and rare earth materials, and research on defect engineering, surface and interface chemistry and nanomaterials for medical sensors. His recent publications focus on zirconium and hafnium compounds, two-dimensional tungsten and molybdenum sulfides, and their applications in electronics and aeronautics industries. 